8.

\title{
Síntese e caracterização de inibidores da deadenilase CAF1 (CNOT7) humana
}

\section{Carolina Terassi ${ }^{\star}$, Hugo M. Shimo,Thiago A. do Nascimento, Silvana A. Rocco, Celso E. Benedetti.}

\section{Resumo}

A proteína CAF1 desempenha função importante no controle da expressão gênica, pois participa do processo de deadenilação da cauda poli(A) de RNA mensageiros (mRNAs), contribuindo assim para a degradação das moléculas de mRNAs. Estudos recentes mostraram uma correlação entre a atividade da proteína CAF1 humana (hCAF1) e a progressão de alguns tumores. Com o objetivo de caracterizar a atividade exonucleásica 3'-5' de hCAF1, hCAF1 foi expressa em bactéria e purificada por cromatografia de afinidade e exclusão molecular. Constatou-se que a atividade exoribonucleásica 3'-5' de hCAF1 requer um íon Mg2+ ou Mn2+ e que a mesma é específica para sequencias de poliadenina. Com o objetivo de identificar compostos orgânicos que possam inibir a atividade de deadenilase de hCAF1, derivados de quinazolinas foram sintetizados e um dos compostos obtidos inibiu a atividade de hCAF1. Com base na estrutura desse composto, novos inibidores estão sendo sintetizados.

Palavras-chave: CAF1; derivados de quinazolinas; inibição enzimática; síntese orgânica.

\section{Introdução}

A proteína CAF1, também conhecida como CNOT7, faz parte do complexo CCR4-NOT que regula a degradação de mRNAs na célula por um processo conhecido como deadenilação da cauda poli(A) do mRNA. Estudos recentes indicam que a atividade enzimática de hCAF1 é requerida para a promoção de metástase. Assim, hCAF1 surge como é um importante alvo terapêutico. Além disso, inibidores de CAF1 com especificidade e potência desejadas ainda não foram descritos para nenhum membro da família CAF $1^{[1]}$. Assim, esse trabalho tem como objetivo principal a identificação de novos inibidores de hCAF1, com ênfase em compostos derivados de anilinoquinazolinas. Análogos de anilinoquianzolinas são amplamente conhecidos por apresentarem diversas propriedades biológicas como anticâncer, anti-inflamatória, antihipertensiva e antidiabética entre outras. [2]

\section{Resultados e Discussão}

Derivados de 2-anilinoquinazolina foram sintetizados pela reação da 4-amino-2-cloro-6,7-dimetoxiquinazolina com a anilina correspondente sob as condições descritas na figura 1. Os compostos foram caracterizados através das análises de seus espectros de RMN e de medidas de ponto de fusão.

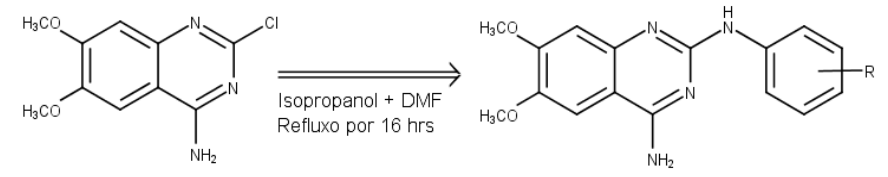

Figura 1. Etapa para a síntese de derivados de 2anilinoquinazolinas $\left(R=\mathrm{F}, \mathrm{Cl}, \mathrm{Br}, \mathrm{I}\right.$, benzilóxi, $\mathrm{OCH}_{3} \mathrm{e}$ outros).

A proteína hCAF1 recombinante foi expressa em E. coli e purificada por cromatografias de afinidade e gel filtração. Os ensaios enzimáticos foram realizados em tampão HEPES 20mM, pH 7.4 contendo $150 \mathrm{mM} \mathrm{NaCl}, 2 \mathrm{mM}$ do íon metálico, $1 \mathrm{mM}$ de DTT, $0.4 \mu \mathrm{M}$ de CAF1 e $2 \mu \mathrm{M}$ da sonda de RNA marcada com fluoresceína na porção 5 '.

A atividade exoribonucleásica 3'-5' de hCAF1 sobre diferentes sondas de RNA contendo uma cauda poli(A), poli(G), poli(C) ou poli(U) foi avaliada em gel de sequenciamento de DNA. Verificou-se que hCAF1 apresenta atividade exoribonucleásica 3'-5' sobre RNA poli(A) (Figura 2), sendo portanto uma deadenilase. Além disso, verificou-se que hCAF1 requer o íon metálico $\mathrm{Mg}^{2+}$ ou $\mathrm{Mn}^{2+}$ para sua atividade.

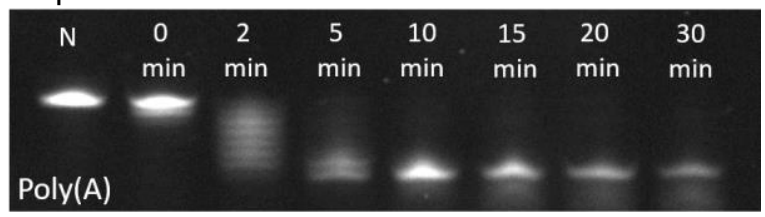

Figura 2. Atividade de hCAF1 sobre RNA poli(A). Notase que em $10 \mathrm{~min}$ a enzima degrada a cauda poli(A).

Ensaios de deadenilação foram realizados na presença de anilinoquinazolinas na concentração de 80 $\mu \mathrm{M}$, e um dos compostos, 26A, inibiu a atividade de hCAF1 (Figura 3).
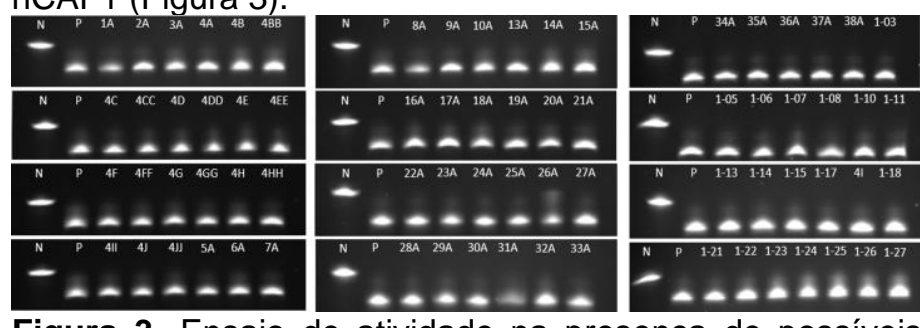

Figura 3. Ensaio de atividade na presença de possíveis inibidores. $O$ ensaio de atividade foi feito controle negativo (sem hCAF1), controle positivo (com hCAF1) e na presença de inibidor em concentração de $80 \mu \mathrm{M}$.

\section{Conclusões}

A hCAF1 é uma deadenilase dependente de $\mathrm{Mg}^{2+}$ ou $\mathrm{Mn}^{2+}$. O composto $26 \mathrm{~A}$ inibiu a atividade de deadenilase de hCAF1 e sua estrutura será utilizada como base para síntese de novas moléculas. Tais moléculas serão testadas quanto as suas propriedades biológicas.

\section{Agradecimentos}

Ao Laboratório Nacional de Biociências do CNPEM e à FAPESP pelo suporte financeiro (2017/07641-2).

${ }^{1}$ Faraji F, Hu Y, Yang HH, Lee MP, Winkler GS, Hafner M, Hunter KW (2016) Post-transcriptional Control of Tumor Cell Autonomous Metastatic Potential by CCR4-NOT Deadenylase CNOT7. PLoS Genet. 12, e1005820. 2 Rewcastle, G. W.; Denny, W. A.; Showalter, H. D. H. (2000) Synthesis of 4(Phenylamino)pyrimidine Derivatives as ATP-Competitive Protein Kinase Inhibitors with Potential for Cancer Chemotherapy. Curr. Org. Chem. 4, 679706. 